\title{
Filme, espelho e caleidoscópio: infância, nulificação, docilidade e medo em Aniki-Bóbó, de Manoel de Oliveira
}

\author{
Frederico Osanam Amorim Lima[1] \\ Paula Maria Guerra Tavares[2]
}

\begin{abstract}
Resumo
A despeito de certa lacuna na historiografia cinematográfica portuguesa - a ausência de trabalhos que aprofundem a leitura histórica de determinado filme -, a proposta aqui é colocar em destaque o filme Aniki-Bóbó (1942) e analisá-lo à luz de uma matriz históricocultural-social. Embora haja uma imensa referência ao filme em notícias de jornais, artigos científicos e livros, Aniki-Bóbó é, quase sempre, estudado como os demais filmes portugueses: em conjunto e/ou em uma visão panorâmica. Portanto, este artigo, ao trabalhar o filme de Manoel de Oliveira, procura responder, ao mesmo tempo, a uma ausência na historiografia e a uma necessidade de compreender o filme como um texto da sociedade e do tempo em que foi produzido, desvelando identidades, histórias e pertenças sociais dessa criação artística.
\end{abstract}

Palavras-chave: sócio-história; cinema; Aniki-Bóbó.

Cinema, mirrors and kaleidoscopes: Infancy, sweetness, oblivion and fear in Anilki-Bóbó by Manoel de Oliveira

\begin{abstract}
Despite the lack of tradition of Portuguese cinematographic history and sociology — that is, the low number of works which take an historic approach to a given movie - we will turn our focus in this text to the movie Aniki-Bóbó (1942), analysing it through an historic, cultural and social lens. However many references to the film in newspapers, journal articles and book, Aniki-Bóbó is almost always placed among other Portuguese films, towards one end or another, as a group or with a panoramic view. Therefore, in approaching Manoel de Oliveira's iconic movie, this article seeks to answer, at the same time, a void in historiography, and a need to understand the film as text, inscribed in the society in which it was produced, laden with identities, histories, and social belongings.
\end{abstract}

Keywords: socio-history; cinema; Aniki-Bóbó.

Film, miroir et kaléidoscope: enfance, annulation, douceur et crainte dans l’Anilki-Bóbó de Manoel de Oliveira

Résumé

Face à une lacune dans l'histoire et la sociologie du cinéma portugais - l'absence de travail qui favorise la lecture d'un film historique particulière -, la proposition ici est de souligner le film Aniki-Bóbó (1942) et l'examiner à la lumière de la matrice historique, culturel et social. Bien qu'il existe de nombreuses références au film dans les journaux, des articles scientifiques et livres, Aniki-Bóbó est presque toujours étudié que d'autres films portugais: en ensemble et/ou dans une vue panoramique. Par conséquence, cet article en travaillant le film de Manoel de Oliveira, cherche à répondre en même temps, à l'absence de l'histoire et à la nécessité de comprendre le film comme un texte de la société et de lépoque à laquelle il a été produit, révélant les identités, des histoires et des affiliations sociales de cette création artistique.

Mots-clés : socio-historique ; cinéma ; Aniki-Bóbó.

Cine, espejo y caleidoscopio: infancia, anulación, mansedumbre y reverencia en Anilki-Bóbó de Manoel de Oliveira

\section{Resumen}

Sin embargo un cierto vacío en la historia y el cine portugués sociología - la ausencia de trabajos que fomentem la lectura histórica de una película en particular -, la propuesta aquí es buscar específicamente a la película Aniki-Bóbó (1942) y revisarla a la luz de matriz histórica, cultural y social. Si bien que hay muchas referencias a la película en noticias de los periódicos, artículos científicos y libros, el Aniki-Bóbó es casi siempre estudiado como otras películas portuguesas: en conjunto y/o nuna visión general. Por lo tanto, este artículo al dirigirse a la película de Manoel de Oliveira, tiene como objetivo responder, mientras a la ausencia de una historia y a una necesidad de entender la película como un texto de sociedad y del tiempo en que fue producido, revelando las identidades, historias y afiliaciones sociales de esta creación artística.

Palabras clave: sociohistórico; cine; Aniki-Bóbó. 
Aniki-Bebé/ Aniki-Bóbó

Passarinho totó

Berimbau, cavaquinho

Salomão/ Sacristão

Tu és polícia/, tu és ladrão.

Aniki-Bóbó, 1942.

\section{Cinema, criação artística e caleidoscópio identitário}

$\mathrm{P}$

ortugal, 1942. Em uma das ruelas do centro antigo da cidade do Porto, um garoto franzino e tímido olha para uma menina debruçada na varanda de seu apartamento. Enciumado, outro garoto dá-lhe um empurrão e corre. O primeiro cai e suja o rosto; o que empurrou, na companhia de outros meninos, ridiculariza; a garota, de início, esboça um ar de preocupação, mas depois ri. Todos, menos a garota, na cena seguinte aparecem entrando em uma escola.

A cena, aparentemente ingênua, mas um pouco rude, se passa na totalidade com crianças. Todas, de alguma forma, pertencentes a uma teia de sensibilidades infantojuvenis que começa a referenciar sua vida no encontro com o outro; que começa a construir ameaças ou prazeres em função desses (des)encontros e que, por fim, sente, com mais intensidade, o peso e o vigor da moral adulta em seus corpos e subjetividades. Essa cena, expressiva de um comportamento infantojuvenil presente em várias partes do mundo no século XX como hoje, é uma das primeiras imagens que se vê no filme Aniki-Bóbó, ${ }^{3}$ de Manoel de Oliveira. Nela, garotos de terna idade e pertencentes a um estrato social mais desfavorecido, a pretexto de brigarem pela atenção de uma menina, são inseridos em uma narrativa que envolve repressão, anulação na constituição de si e produção do medo, fonte de insegurança ontológica e estatutária.

Mais do que um filme que pretende, segundo seu próprio idealizador, "sugerir uma mensagem de amor e compreensão do semelhante, como advertência a uma sociedade que luta e se desespera em injustiças", ${ }^{4}$ Aniki-Bóbó é uma película catártica. Não porque expresse a mudança de sentimentos de seu personagem principal. Nem por provocar alterações de sentido e emoções em quem assiste. Mas por alertar para os processos de nulificação a que estamos submetidos e que não são facilmente reconhecidos. Também por insinuar os começos históricos da docilidade, do medo e da apatia em uma sociedade e o quanto a felicidade pode ser uma faceta cruel da repressão. É, por fim, catártico porque, no caso português, mostra o começo histórico de uma possível sen-

${ }^{3}$ Oliveira e Ribeiro (1942). O argumento do filme, segundo o site IMDB e pelas palavras de Guy Bellinger, centra-se no seguinte: "the story takes place in the old streets of Porto and by the banks of the Douro River. A gang of very young kids has just accepted a new member, Carlitos, a shy boy who has 'played it tough' by stealing a doll in a shop. Carlitos soon develops a crush on Terezinha, the only girl of the group. The trouble is that Eduardo, the 'boss', is also in love with the pretty little girl. And he will not allow any rival to challenge him...". Disponivel em: <http://www.imdb.com/title/tt0034461/plotsummary?ref_tt_ov_pl>. Acesso em: 18 jan. 2016.

${ }^{4}$ Disponivel em: <https://centroculturaldaponte.wordpress.com/2011/06/02/notas-sobre-o-cinedebate-com-ofilme-aniki-bobo/>. Acesso em: 15 set. 2015. 
sibilidade leniente, metaforizada, no filme, na vida de crianças supostamente felizes, mas amordaçadas a rígidos sistemas disciplinares.

Aqui, assume particular relevo referir a época histórica vivenciada em Portugal, o Estado Novo, e todo o seu sistema simbólico-ideológico repressivo assente em um imaginário de fechamento e de apatia em face do exterior e de seus ventos de mudança. Em termos socioeconômicos, Portugal apresentavase como uma sociedade marcada pela ruralidade, pelo fechamento social e cultural, pelo fato de as populações terem, na generalidade, uma escolaridade muito baixa; enfim, uma sociedade profundamente fechada e desigualitária, na qual existia um acesso aos meios de informação e comunicação reduzido, em que a cultura de massas não tinha qualquer enquadramento (Loff, Piedade e Soutelo, 2015; Guerra, 2010). A descrição de António Barreto é exemplar a esse título:

[...] a sociedade rural do interior, provinciana, patriarcal, de patrocinato local, vivendo com elevadas percentagens de autoconsumo, por vezes até com agricultura de subsistência, arredada dos grandes serviços públicos, à margem da proteção social do Estado, sem serviços de saúde na comunidade, com reduzidas possibilidades de frequentar a escola, com mínimo acesso à comunicação ou à informação, sem correios nem serviços bancários, com estreitas vias de consumo e expressão cultural, por vezes nem sequer inteiramente integrada no mercado, cultivando valores próximos dos que poderiam vigorar no Ancien Régime. (Barreto, 1995, p. 843)

Portugal, 1930. A capa da revista Presença, Folha de Arte e Crítica, de agostooutubro de 1930, tem como imagem central o desenho de uma mulher voluptuosa, de traços desproporcionais, puxando uma criança que quase desaparece por trás de sua vestimenta. No fundo, uma ladeira, possivelmente inspirada em alguma parte da zona ribeirinha do Porto, com um casal conversando e um gato preto no centro. Na página seguinte, escrito com letras que sugestionam sinais gráficos recém-aprendidos, o título de um conto do advogado e escritor português Rodrigues de Freitas: "Os meninos milionários na sala de aula".

O conto, que tem uma segunda parte publicada cinco anos depois na mesma revista, narra a história de crianças ribeirinhas que estão presas a cenários sem cor e vida. Na primeira parte da história, o espaço da sala de aula subjuga as crianças e concebe-lhes um papel secundário. A sala, espaço por excelência da divulgação/produção de conhecimento, é, no conto de Rodrigues de Freitas, um lugar amorfo e triste, "que tem quatro paredes brancas [...] e onde há moscas que lembram manchas de tinta sobre papel, moscas que parecem coladas, vivas e, afinal, estão mortas". Nesse espaço de "quatro muros que nos fecham", as crianças pairam sentadas, "de rosto imóvel, em frente dos livros abertos" (Freitas, 1930, p. 2).

Primeira e relativamente fácil constatação: a palavra que mais aparece nas duas partes do conto é "medo". Rodrigues fala do rio onde as crianças "passam 
as tardes a nadar nus, com medo da polícia"; conta das árvores onde eles sobem para roubar frutos, mas que sobem "com medo dos jardineiros"; descreve a construção dos medos a partir das histórias que ouvem dos adultos, da criação dos espectros e diabos que, imaginariamente, os perseguem; que sentem medo quando correm, tarde da noite, pelas ruelas escuras e sem som na brincadeira de polícia e ladrão (Freitas, 1930, p. 2-3). Habita neles "o medo da noite, do silêncio e das sombras"; por fim, um medo que alimenta uma corrida de fuga contra seus pavores subjetivos, uma "corrida desenfreada", motivada pelo "medo [que] cresce cada vez mais [...] para fugir aos seus fantasmas e pavores" (Freitas, 1935, p. 3 e 7).

O conto "Meninos milionários", como ficou conhecido, no entanto, toma o medo não como um sentimento que inibe e promove a sujeição. O medo, no conto, é o substrato de um comportamento de revolta e contestação. O medo é a sensação que desperta a fuga, as táticas infantis, as pequenas insurreições contra as autoridades, o próprio desejo de liberdade (Certeau, 1994). "Meninos milionários" é um tratado de liberdade transformado em conto por Rodrigues de Freitas no momento em que se consolidam as instituições disciplinares em Portugal e o "poder" se pulveriza por toda a sociedade.

Este artigo, na tentativa de desvelar os meandros do poder que produzem determinadas sensibilidades infantojuvenis em Portugal nos anos 1930 e 1940, a partir do filme Aniki-Bóbó e dos rastros da criação de seu argumento, segue uma premissa teórica que, em primeiro lugar, entende as obras de arte, as criações artísticas como textos identitários, como conteúdos culturais. Assim, operamos neste artigo uma espécie de duplo movimento: em busca da profundidade para dentro dos conteúdos da obra cultural Aniki-Bóbó e na procura da extensão, pela multiplicação dos ângulos de aproximação à obra cultural "Meninos milionários" na senda de Auerbach (1946), Panofsky (1951), Calvino (1998) e Said (1979). Dentro dessa filiação teórica, é impossível não ceder ao desafio de reinterpretar as criações artísticas (filmes, textos literários, músicas) como catalisadores de identidades, reconhecendo a produção de subjetividades como resultado de um cálculo intercedido por micropoderes quotidianos. Aqui emerge a segunda premissa teórica de base: entender o "homem" como uma produção subjetiva mediada pelo poder.

Não necessariamente um poder que agride, que repreende publicamente, que castiga em demasia. Mas um poder que se revela no estímulo à repetição de bons exemplos (ao modelo de uma historia magistra vitae), no olhar de censura proveniente dos outros, nos cerceamentos diários que objetivam a produção da docilidade, e, também, nas pequenas cordialidades do dia a dia e afabilidades excessivas (Foucault, 1984 e 2013). Um poder que se constrói e se manifesta nas relações diárias entre os homens e as instituições; e que, por fim, não pertence a ninguém, mas se manifesta nas relações cotidianas e de uma forma nem sempre explícita e reconhecível (Foucault, 1999). Enfim, uma microfísica de poder simbólico no sentido bourdeusiano também. Assim, segundo Pierre Bourdieu, o poder simbólico é: 
[...] um poder de construção da realidade que tende a estabelecer uma ordem gnoseológica: o sentido imediato do mundo [...], quer dizer, "uma concepção homogênea do tempo, do espaço, do número, da causa, que torna possível a concordância entre as inteligências". [...] O poder simbólico, poder subordinado, é uma forma transformada, quer dizer, irreconhecível, transfigurada e legitimada, das outras formas de poder: só se pode passar para além da alternativa dos modelos energéticos que descrevem as relações sociais como relações de força e dos modelos cibernéticos que fazem delas relações de comunicação, na condição de se descreverem as leis de transformação que regem a transmutação das diferentes espécies de capital em capital simbólico e, em especial, o trabalho de simulação e de transfiguração. (Bourdieu, 1989, p. 9 e 15)

Por nulificado e dócil, portanto, seguindo essa linha teórica, entendemos aquele comportamento - manifestado de forma literária especialmente na obra do escritor checo Franz Kafka - expresso na repetição do bom comportamento, na continuidade da norma, nas pequenas obediências do dia a dia e na tensão criada à espera das consequências do que se fez ou falou. De um comportamento que é sentenciado pelo peso de uma lei que está para além dos tribunais e suas sentenças. De uma lei que prescinde o crime. Uma lei que sentencia uma vida a constantes obrigações. Uma lei que pune diariamente, que sutura o comportamento ao padrão e que faz dos olhares de reprovação de muitos verdadeiros tribunais em defesa de uma moral, de uma ética. Uma das questões que aproximam Bourdieu e Wittgenstein é a consciência da ambiguidade contida na noção de regra, frequentemente usada em situações e com significados bastante distintos. Wittgenstein é pioneiro ao atacar aquilo que considera ser a "mitologia das regras". Por um lado, critica a ideia da linguagem como um cálculo baseado em regras bem-definidas; por outro, critica a concepção mecanicista frequentemente associada aos casos em que estão em causa regras explícitas e ambivalentes (como as regras matemáticas), que determinariam sempre as ações a realizar, qualquer que fosse a situação. Por razões óbvias, Bourdieu é também muito sensível à discussão em torno da noção de "regra" e da confusão gerada pela existência de dois usos diferentes dessa noção: o da regra como hipótese explanatória formulada pelo teórico para explicar o que vê e o da regra como princípio que realmente governa a prática dos agentes. No jogo social, existem padrões de comportamentos regularizados, ou seja, padrões de comportamentos que resultam da obediência a regras reconhecidas e codificadas cotidianamente. A obediência a essas regras é intencional e acarreta conhecimento e compreensão das implicações da regra e das implicações da obediência à regra. Por outro lado, existem regularidades nos comportamentos que apenas podem ser explicadas de modo puramente causal, com a ajuda da ideia de existência de "mecanismos" sociais profundos responsáveis por nosso comportamento, espontâneo e "inconsciente" (Bourdieu, 2002). 
Aniki-Bóbó, um filme, vale a pena ressaltar, de 1942, além de expressar a vivência de jovens ribeirinhos que começam a descobrir as pequenas paixões, é uma película que revela a presença de uma cidade marcada pela iminência das punições e dos desvios que são expressos em possibilidades de castigo. E também do exemplo que deve ser seguido como forma de manutenção do mundo adulto socialmente aceito. Um filme que revela, entre outras coisas, a conservação e a manutenção de uma sociedade disciplinar, sustentada na punição, na vigilância constante, na produção do medo e na legitimação social do comportamento ordeiro, nulo e dócil em um profundo aparato bourdeusiano de símbolos de poder(es):

[...] os símbolos são os instrumentos por excelência da "integração social": enquanto instrumentos de conhecimento e de comunicação [...], eles tornam possível o consensus acerca do sentido do mundo social que contribui fundamentalmente para a reprodução da ordem social: a integração "lógica" é a condição da integração "moral". (Bourdieu, 1989, p. 10)

Acima de tudo, revela uma cidade estratificada em classes (e fracções de classes) sociais perpetuadora de clivagens reais e simbólicas muito para além da dualidade marxiana, burguesia e proletariado. Em Aniki-Bobó, Carlitos, Eduardito, Teresinha, Pistarim, personagens centrais da trama de Manoel de Oliveira, carregam em suas vestimentas, brincadeiras, sonhos e frustrações a reprodução de uma condição social na qual seus lugares já foram, por força simbólica e material, definidos ao nascimento e se prolongarão pelo resto da vida. O próprio argumento e conflito em torno do qual o filme se desenrola é um bom exemplo disso: Carlitos, garoto franzino, sem posses, imerso em uma tradição familiar que repete em gestos e expressões a ideia de que os valores e princípios são declarações de dignidade, bem mais que o dinheiro, se apaixona por Teresinha. Eduardito, criança mais forte e trajando vestimentas que denunciam um lugar de classe mais favorecido, também sente atração por Teresinha. $\mathrm{O}$ embate, sustentado em uma narrativa tradicional de conquistas amorosas, com direito a disputas, ofensas e brigas, terá como móbil uma boneca. Teresinha, única criança com papel de mulher no filme, se encanta por uma boneca posicionada no centro da vitrine de uma loja. Carlitos reconhece no brinquedo a possibilidade de ter a atenção de Teresinha e afastar a ameaça de Eduardito.

A boneca, portanto, é o pretexto sobre o qual o novo símbolo de uma moral é (re)produzido: um objeto deve carregar consigo a medida de um sentimento. A boneca deve conter tudo aquilo que as manifestações de afeto de Carlitos não conseguem contemplar. E mais, ela deve reduzir as chances de Eduardito ao enunciar que o objeto, cujo valor sentimental para Teresinha era grande, veio das mãos de Carlitos. Por outro lado, a posse da boneca, dadas as condições sociais de Carlitos, só é possível por intermédio de algo ilícito. Sem Teresinha e Pistarim, seu melhor amigo, saberem, o garoto furta a boneca: novo signo de um desfavorecimento social. Nesse momento, todo aquele lastro de dignidade familiar que ele devia carregar, expresso na própria inscrição costurada em sua 
bolsa - "segue sempre por bom caminho" —, se esvai. Carlitos viverá, a partir de então, imerso em um cenário de culpa, frustração e medo. Mergulhado em sentimentos que são revelados, no filme, na construção de uma cidade panóptica, portadora de uma sociedade vigilante e de um quotidiano de constantes e variadas fiscalizações. Carlitos passa a ter medo de todos e aponta essa aflição em corridas, olhares desconfiados e fugas.

\section{Aniki-Bóbó (...) é uma película que revela a presença de uma cidade marcada pela iminência das punições e dos desvios que são expressos em possibilidades de castigo}

Como produto de uma época e lugar, Aniki-Bóbó é o resultado, em uma produção visual, de um tipo de sociedade em que se pulverizaram as marcas do poder. Nesse modelo de sociedade, manifestado na existência e multiplicação dos "signos-obstáculos", como diz Foucault, responsáveis pela produção de uma cidade onde nada passa alheio aos micropoderes, os discursos que legitimam a ordem e o bom funcionamento da vida em grupo devem funcionar como uma mecânica capaz de "travar o desejo do crime pelo medo calculado do castigo" por meio de "mil pequenos teatros de castigos" (Foucault, 2013, p. 131). Nos papéis sociais, nos letreiros, nas salas de aula, nos símbolos, em tudo, enfim, devem prescindir a marca e os signos de um código de comportamento socialmente aceito: "em redor de cada uma destas 'representações morais', os alunos acotovelar-se-ão com os seus professores e os adultos aprenderão que lições devem ensinar aos filhos" (Foucault, 2013, p. 132).

Por outro lado, em uma leitura a contrapelo dessa condição histórica, é possível reconhecer que do interior dessa sociedade rígida e disciplinar produz-se, no âmbito do quotidiano, uma ação reativa aos micropoderes e suas normas e regras. Se Aniki-Bóbó é a expressão de uma sociedade que se fecha em torno de uma faceta austera que revela os meandros do poder pelo viés de suas armadilhas, o conto "Meninos milionários" revela o caminho inverso: é no quotidiano que a vida se faz e que se torna possível ludibriar o poder em um jogo de táticas e astúcias cotidianas. Por meio de gestos, aparentemente inocentes e infantis, operaram-se táticas que afrontam os signos do poder. Nessa outra premissa teórica - que não anula as primeiras, ao contrário, as complementa —, o homem ordinariamente escapa aos aprisionamentos, revelando astúcias capazes de transformar inclusive o medo em um sentimento potencialmente rico de contestação e reinvenção cotidiana (Certeau, 1994).

\section{Aniki-Bóbó e os "Meninos milionários": um filme construído a partir de um conto ou uma história que desarmou o conto?}

As narrativas sobre o filme começam, geralmente, assim: “Aniki-Bóbó é a primeira longa-metragem e primeira obra de ficção de Manuel de Oliveira, 
adaptação de um conto da autoria de Rodrigues de Freitas, intitulado 'Meninos Milionários." ${ }^{5} \mathrm{Ou}$, como no livro que é parte de um projeto de "ver" o Porto pelas imagens produzidas por cineastas, assim:

A Ribeira não é já aqui o palco do mundo do trabalho e do árduo quotidiano dos improvisados "estivadores" dos produtos que chegavam ao cais portuense do rio. É antes o "recreio" das brincadeiras dos "Meninos Milionários" - o título do conto de Rodrigues de Freitas que está na origem do filme. (Andrade, 2002, p. 46)

Ou, ainda, como no site de promoção turístico-visual do Porto, feelporto, desta forma: "Aniki-Bóbó é um filme português de 1942, realizado por Manoel de Oliveira, num dos olhares mais ternos sobre o Porto antigo [...]. Adaptado de Os Meninos Milionários, do escritor e advogado João Rodrigues de Freitas (1908-1976) [...]." ${ }^{\prime 6}$ O que salta aos olhos na maior parte das notícias alusivas ao filme é a referência, quase "necessária e justa", à ideia de que Aniki-Bóbó foi "construído a partir da fábula meninos milionários, do advogado e escritor português João Rodrigues de Freitas". Notícias aparentemente ingênuas e despretensiosas, mas que, a tomar pela grande incidência de referências a dois pontos principais, permitem levantar duas questões fundamentais: primeiro, por que abreviar a referência ao conto de João Rodrigues de Freitas apenas a uma dimensão simbólica de texto que foi "adaptado" ou está na "origem" do filme? Segundo, como se construiu, historicamente, a imagem de Aniki-Bóbó como filme-síntese do cinema português? São perguntas que, embora sejam situadas como centrais nesse ponto, possivelmente funcionarão como questões norteadoras para provocações, muito mais do que para respostas. Portanto, a pretensão, pelo menos neste momento, não é responder propriamente a essas perguntas, mas, antes, levantar alguns problemas sobre os modos de funcionamento da historiografia do cinema português, com destaque para aquela que tomou Aniki-Bóbó como tema, e como isso acabou por não conduzir a uma leitura do filme a partir dos meandros da sócio-história do poder que estão no centro da narrativa de Manoel de Oliveira aqui.

Aniki-Bóbó, apesar de figurar entre os filmes mais comentados do cinema português, carece, ainda, de uma bibliografia específica. De forma mais pontual e densa, basicamente só existe, na histografia cinematográfica portuguesa, o livro de Manuel António Pina, Aniki-Bóbó, lançado em 2012. No entanto, esse livro é, tanto quanto o filme, metafórico e poético. Escrito na forma de um ensaio, a obra é taxativa ao apresentar Aniki-Bóbó como "um clássico do cinema português, provavelmente $o$ clássico do cinema português", isso porque, ainda segundo Manuel António Pina, clássico é “a obra que, 'revelando' o seu tempo, o seu tempo no entanto não se esgota” (Pina, 2015, p. 61). De saída, o filme de Manoel de Oliveira é apontado como pertencente a uma matriz fílmica que

Disponível em: <http://www.outrapresenca.com/index.php/seccoes/artes-e-letras/leituras/247-aniki-boboamores-e-desamores-de-um-grupo-de-jovens-portuenses>. Acesso em: 6 out. 2015.

${ }^{6}$ Disponível em: <http://www.feelporto.com/aniki-bobo/>. Acesso em: 6 out. 2015. 
merece reconhecimento pelo caráter atemporal. Produto de uma época e de uma sociedade, o filme, "clássico" para Pina, sugestiona questões que atravessam o tempo e revelam uma ambiência sócio-político-cultural sempre atual.

Salvo o lugar de destaque que a obra de Manoel de Oliveira tem e a prescrição estética e histórica que Aniki-Bóbó tem no livro, o que chama a atenção - denunciando certo padrão de apresentação da ligação do filme com o texto de Rodrigues de Freitas - é a simples, rápida e advertida ligação entre o filme e o conto. Nas palavras de Pina, o realizador de Aniki-Bóbó, para escrever seu argumento, "foi justamente inspirar-se num conto - no genérico do filme chama-se-lhe 'poema' - da autoria de Rodrigues de Freitas publicado nos números 28 e 44 da Presença" (Pina, 2015, p. 17). Note-se que, como apresentamos anteriormente, existe certa enunciação de palavras e de contextos para anunciar a relação entre o conto e o filme. Pina, entretanto, não deixa brecha para qualquer interpretação que eleve o conto a uma dimensão mais grandiloquente que o filme:

[...] "inspirado" parece, de fato, um termo adequado. Do conto (ou "poema"), intitulado "Os meninos milionários", Oliveira aproveitou, além de um ou outro pormenor narrativo e de brevíssimas manchas de diálogo, sobretudo [...] o tema poético da oposição entre o mundo fechado, conformador e repressivo da escola e o universo livre da rua e do rio, territórios abertos das brincadeiras e dos sonhos. (Pina, 2015, p. 17)

Além de constar apenas como uma nota no capítulo que insere o filme no diálogo com seu tempo, o que chamou a atenção nos textos sobre Aniki-Bóbó foi o deliberado desinteresse dos investigadores e escritores do cinema português em apresentar o conto de Rodrigues de Freitas. Na análise de discursos, "a gramática ajuda, mas também esconde" (Silva, 2011, p. 73). O que se fala ou se escreve, portanto, na medida em que aponta caminhos interpretativos e/ ou explicativos, encobre ou mesmo ignora outras paisagens e cenários elucidativos. Assim, os discursos são também tomadas de poder, formas de interpretação e representação do real assentes, além de interesses, subjetividades e percursos identitários. Não é difícil, portanto, projetar certa precaução por parte dos escritores em avaliar a importância de "Os meninos milionários" em face do filme de Oliveira, ou mesmo justificar o conto como um repositório de informações históricas. Aliás, sobre o conto e o próprio Rodrigues de Freitas há pouca ou nenhuma coisa escrita. ${ }^{7}$ Já sobre Manoel de Oliveira e seus filmes, como dissemos, existe imensa bibliografia. Portanto, no que diz

7 Sobre o esquecimento de Rodrigues de Freitas, inclusive seu irmão, António Freitas, se manifestou publicamente em uma entrevista concedida à RTP dizendo, entre outras coisas, que fica "um bocado triste que tanto se fale do Oliveira, por tudo e por nada, para aqui e para acolá, e que nunca ninguém se lembre do meu irmão, porque foi ele que escreveu o conto 'Os Meninos Milionários"'. Além disso, chama a atenção para a participação política do irmão, dizendo "que na política, na oposição a Salazar, foi membro do MUD - Movimento de Unidade Democrática, de cuja juventude Mário Soares foi militante destacado. Chegou a ser preso pela Pide [Polícia Internacional e de Defesa do Estado] durante umas semanas, mas foi libertado". Disponivel em: <http://www.rtp.pt/noticias/cultura/rodrigues-de-freitas-autor-do-conto-que-inspirou-anikibobo-injustamente-esquecido_n168394>. Acesso em: 17 set. 2015. 
respeito a Aniki-Bóbó, na construção e manutenção de sua condição como filme-sintese, deve prevalecer, sobretudo, seu sentido original como produto da genialidade de Manoel. É possível asseverar, neste momento, que os "discursos sobre" nos permitem aceder ao que cada locutor pensa, crê, espera e diz da obra. Esse exercício é fundamental, porque funda a legitimidade artística, descobrindo (encobrindo) uma oposição binária fundamental entre o que é "ser importante" e o que é ser "secundário".

Uma das pesquisadoras mais importantes sobre o cinema português, Carolin Ferreira - não obstante não ter um livro específico sobre Aniki-Bóbó - , dedica, em alguns de seus textos, uma atenção especial ao filme. Em um de seus livros, aquele, possivelmente, de introdução para muitos estudiosos no cinema português, Carolin Ferreira aponta para um caminho interpretativo do cinema luso que contraria categorias habituais. Não há no livro O cinema português: aproximações à sua história e interdisciplinaridade uma indicação de que o cinema português, e de forma especial os filmes de Manoel de Oliveira, estejam inseridos em categorias como "cinema clássico", “moderno", "pós-moderno" (Ferreira, 2013). Carolin Ferreira, em geral, toma por referências discussões mais temáticas. São questões como os debates da geopolítica que os filmes sugerem; a questão da identidade portuguesa; o local/nacional/global; a condição humana e as questões de gênero, por exemplo. Aniki-Bóbó, dentro dessa configuração temática, seria um filme em que aspectos da cultura nacional portuguesa deveriam ser tomados, na perspectiva de Manoel de Oliveira, como algo importante a oferecer ao mundo. Simplificadamente, o filme pode ser inserido em um diálogo local/nacional. Embora não seja esse o ponto que merece mais destaque, merece atenção por configurar um aspecto importante na engrenagem histórico-discursiva em torno da composição da ideia de filme-síntese para Aniki-Bóbó.

Especificamente sobre o filme, Carolin Ferreira recorre novamente a essa espécie de lugar-comum para apresentar o filme: "O filme, baseado num conto de Rodrigues de Freitas, Meninos Milionários, debate a relação entre liberdade e expressão através de um grupo de crianças que moram na mesma Ribeira" (Ferreira, 2013, p. 139). Novamente, o conto de Rodrigues de Freitas é suprimido e sua menção não merece mais do que duas linhas. Em torno de AnikiBóbó, entretanto, consolida-se uma atmosfera de sublimação que não deve despertar a dúvida, a suspeição e a problematização. Há, ao que parece, um regime de discursividade consolidado em torno do filme que: 1) reduz o conto de Rodrigues de Freitas a uma mera nota de rodapé, minimizando sua importância e, no máximo, entendendo sua influência como algo secundário e/ou desimportante; 2) Aniki-Bóbó é, por excelência, um filme que sintetiza as marcas mais expressivas do que se deseja apresentar sobre o cinema português, nomeadamente aquele que antecede o Cinema Novo português; 3 ) nessas marcas estaria outro regime de discursividade que tenta imprimir certa leitura do filme como "a mais correta". Sobre este último ponto, o livro de Carolin Ferreira expressa, de uma forma concisa, os elementos sobre os quais se espera que 
o filme seja lido. Para a autora, assim como, inclusive, para Manuel António Pina, Sérgio C. Andrade, entre outros, o filme:

[...] demonstra os diferentes degraus de contenção do comportamento humano, que revelam o seu possível excesso: transgressão e redenção fazem parte da vida humana e são regulamentados através de um sentimento moral que se expressa, principalmente, através da consciência [...], e, por isso, não se justificam medidas disciplinares extremas e repressivas. (Ferreira, 2013, p. 140)

Se nos detivermos no padrão de discursividade sobre Aniki-Bóbó, poderemos aquilatar que o filme revela com bastante simplicidade a dimensão humanista e solidária por detrás de um cenário de guerra e conflitos sociais; Aniki é, para esses autores, um filme "lírico e intuitivo: é através da desmesura do olhar infantil que tal universo se nos revela e é pela inocência transformadora desse olhar primeiro que ele ganha 'força poética"' (Pina, 2015, p. 25). Sérgio C. Andrade, como a seguir a prescrição, aponta em Aniki as mesmas questões levantadas por Carolin Ferreira e Manuel António Pina. Assim, Aniki-Bóbó é um dos filmes de Manoel no qual as dimensões na natureza humana se revelam com maior nitidez e quase de forma evidente: “Aniki-Bóbó não trata, no entanto, de uma anódina história de brincadeiras de crianças; é antes um retrato das várias facetas da natureza humana. O próprio realizador considera que 'a criança é um adulto em potência"' (Andrade, 2002, p. 46).

O segundo ponto no texto de Carolin Ferreira, por sua vez, deixa uma brecha para pensar a disciplina que transcorre não de medidas extremas e diretamente repressivas, mas, por outro lado, o controle que se supõe na própria falta de uma correção do ato infracional. Aniki-Bóbó, nesse sentido, revela como determinada sociedade aceita os efeitos do poder, como aceita subjugar seus atos e desejos e amarrá-los a uma moral maior, seja ela propagada pelas instituições do Estado ou por algum substrato sociocultural. Esse ponto, entretanto, é negligenciado ou deliberadamente abandonado pela crítica e historiografia do cinema português citada. ${ }^{8}$ Ao tomar a dimensão humanista, de valorização da "natureza humana", da dimensão poética e quase litúrgica do filme, o que essa leitura não favorece é um olhar crítico sobre o tempo de produção da película e a signagem sociocultural em que ela está inserida. É, portanto, justamente na brecha que essa citação de Carolin Ferreira abre que pensamos ser possível ler Aniki-Bóbó como uma produção artística cujas marcas revelam traços identitários de uma sociedade e tempo.

Ressaltado o lugar intertextual entre filme e conto, no qual existe, como se tenta mostrar, "um elo na corrente complexamente organizada de outros enunciados", como os que reverberam da sociedade para a obra de arte e destas para a historiografia, outro ponto de conexão entre os autores apontados diz respeito à forma como a obra foi recebida pela crítica (Bakhtin, 2003, p. 272). Sublinhamos, outrossim, que não existem trabalhos e investigações que

${ }^{8}$ Além dela, vale ressaltar, também, sua ausência em livros como: Araújo (2014) e Correia (2015). 
se proponham pensar Aniki-Bóbó dentro de uma ótica de estética da recepção. Nem é, neste momento, objetivo deste artigo. No entanto, para dar vazão à dimensão quase mítica da obra de Manoel de Oliveira, vale ressaltar adiante a forma como a historiografia portuguesa discute a recepção do filme.

\section{Cartografias de um poder retalhado: sujeitos, olhares e gestos de repressão em espelho}

Filmado e exibido em 1941-1942, no meio da Segunda Guerra Mundial e em um momento de consolidação do Estado Novo em Portugal — com mais uma reeleição e posse de Óscar Carmona —, o filme tem narrativa relativamente simples. No entanto, como carrega as marcas de seu tempo, de sua sociedade e cultura, Aniki-Bóbó revela, por entre cenas aparentemente ingênuas e despretensiosas, a microfísica do poder que aquieta subjetividades rebeldes; que disciplina e dociliza o diferente; que marca os corpos com valores e morais aceitos socialmente, como evidenciamos na primeira seção deste artigo.

\section{Aniki-Bóbó é um filme que sintetiza as marcas mais expressivas do que se deseja apresentar sobre o cinema português, nomeadamente aquele que antecede $o$ Cinema Novo português}

É um filme, por sua vez, que fala sobre o peso da autoridade na constituição das subjetividades ainda na infância. Uma autoridade que começa, não por acaso, com a mãe, nas punições diárias e nas palavras de ordem. A mãe, que se constitui no primeiro referente de poder sobre o indivíduo, segue, logo na primeira cena do filme, uma prescrição familiar burguesa, sendo aquela responsável pela correção dos equívocos/erros do filho e do cuidado com sua educação (Silvia e Koller, 2006). Carlitos, personagem central do filme e sob o qual recairá o peso de todas as demais relações de poder existentes na película, carrega, ao sair de casa, parte da carga punitiva de sua sociedade e tempo, pensada para não ser, necessariamente, um fardo, mas um preceito educacional e valorativo. Aqui, Aniki entra no plano das criações culturais na exata medida em que:

[...] são criações culturais, no sentido forte do termo, que podem ser descritas como "textos", quer dizer, como estruturas de significação que se combinam em obras singulares e duradouras, sujeitas à dialética das representações de autores, intérpretes e receptores, no quadro de referência de certas comunidades e contextos de criação, valoração, intermediação e consumo. (Silva e Guerra, 2015, p. 75) 
Toda essa instituição disciplinar imanente em Aniki culmina em determinada moral cuja expressão máxima está inscrita na frase da bolsa que ele carrega, entregue, exatamente, por sua mãe: "segue sempre por bom caminho". Trata-se, logo no início, de uma insinuação categórica de que é fundamental a escolha de um trajeto de formação ética e moral sustentada em exemplos que denotem o comportamento ordeiro e salutar. De um "preceito moral que, como um fantasma maternal, permanentemente o acompanha e vigia: 'segue sempre por bom caminho"' (Pina, 2015 p. 31). A comparação, a tomada de postura ambientada no olhar alheio, a autoavaliação de sua atitude físico-comportamental, que se repreende em busca de um modelo de comportamento aceitável, são expressas em uma economia das trocas simbólicas do poder (Foucault, 1984 e 2013; Bourdieu, 1989). Uma economia do poder na qual a frase "segue sempre por bom caminho" é uma de suas manifestações mais simbólicas.

O filme, como se disse, é expressivo de signos de um modelo de sociedade regulada por padrões e rígidos sistemas disciplinares. Na sequência à despedida da mãe, por exemplo, Carlitos entra em choque com o novo referente de poder institucional. Ao andar desatento pela rua, acaba esbarrando em um policial. Como agente do Estado que aparece com frequência e de forma inusitada em várias partes do filme, está ali para demonstrar que a fiscalização dos atos do indivíduo é constante; que ele é capaz de coagir, reprimir e punir; mas, acima de tudo, o policial está presente, nessa narrativa envolta em um conto de crianças, para legitimar a ideia de que o poder está em toda parte. Para informar que sua presença é marca de um poder institucionalizado; e para dizer, também, que sua ausência deve despertar um sentimento de vigilância constante. Que interfere em seu corpo, em sua fala e, inclusive, em seus sonhos.

Com a polícia estamos no indefinido de um controle que procura idealmente atingir a partícula mais elementar, o fenômeno mais passageiro do corpo social [...]. E para se exercer, esse poder deve adquirir o instrumento para uma vigilância permanente, exaustiva, onipresente, capaz de tornar tudo visível, mas com a condição de se tornar ela mesma invisível. Deve ser como um olhar sem rosto que transforme todo o corpo social em um campo de percepção [...]. (Foucault, 2013, p. 245-246)

Em uma perspectiva inversa àquela contida no conto de Rodrigues de Freitas, Aniki-Bóbó chama a atenção para o medo como um sentimento de apatia, que provoca a subjetivação do receio, do temor e da mensuração dos atos. O medo, como instrumento de fabricação dos pavores sociais, é alimentado pelas punições na escola, pelo receio, que Carlitos sente de não ser integrado ao grupo de amigos e pelo tormento que lhe aflige após o furto da boneca. Um tipo de medo que inspira a nulificação. Que não é potência criadora nem arauto de forças rebeldes. $\mathrm{O}$ medo, no filme, é expressão de um universo social imerso em uma teia de conservadorismos, obrigações e saberes que conduzem ao padrão sob o risco de punições diárias - como a frase "não torno a faltar à escola", escrita no caderno, anotada à exaustão pelos alunos, como forma de punição. 
Retomando a boneca: o que se segue ao furto da boneca é uma sucessão de episódios que colocam em alerta constante a moral e os valores que Carlitos carrega consigo. No afã de descobrir o autor do furto, o vendedor da loja faz digressões, recorda a presença de crianças nas imediações de sua loja e em seu interior, especula sobre a integridade moral inclusive do próprio filho. Enquanto isso, Carlitos é arrastado, em cena, para a brincadeira que é mote do filme. Ao usar a brincadeira de "polícia" e "ladrão", Manoel de Oliveira alimenta a aflição de Carlitos quando, na escolha entre quem persegue e quem será perseguido, o garoto é escolhido como ladrão. ${ }^{9}$ Quando a brincadeira começa, ele, atordoado, corre pelas ruas estreitas do Porto em um cenário sombrio, escuta vozes, imagina ser capturado, enfim, ele está, definitivamente, imerso em um espetáculo visual que transmite angústia e preocupação constantes.

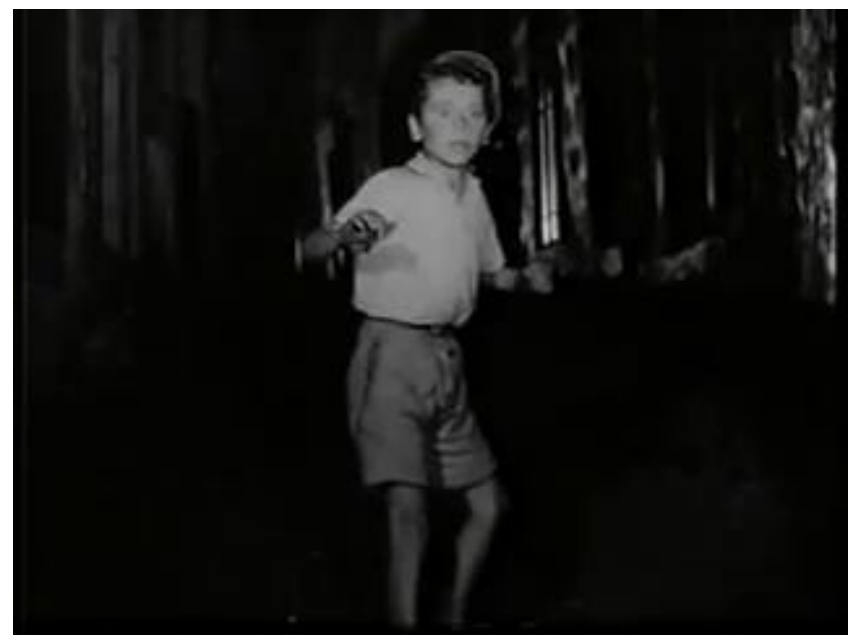

Figura 1. Carlitos, aflito, na brincadeira Aniki-Bóbó. Fotograma de Aniki-Bóbó, 1942

Atormentado pelo furto, tudo prefigura tensão para Carlitos. Sua relação com Teresinha, alimentada na entrega na boneca, ganha mais um contorno dramático com o acidente envolvendo Eduardito. Como brincadeira habitual, todas as vezes que o trem passava apitando os garotos corriam, aos gritos e pulos, para observá-lo. Eduardito, acidentalmente, na ocasião em que poucos segundos antes brigava com Carlitos, cai de cima de uma ribanceira. Olhares, dedos apontados, gestos, tudo incrimina Carlitos. Teresinha é a primeira a reconhecer a queda de Eduardito como artefato criminoso do garoto. Na escola, ele é rejeitado, observado com olhares acusatórios e, ausência de um autor confesso de ter empurrado Eduardito, é castigado junto com os outros. A única pessoa que tem a capacidade de desfazer o equívoco do acidente é o dono da loja onde a boneca foi furtada, que assistiu a distância a todo o desenrolar

\footnotetext{
9 "Aniki-Bóbó", bricadeira cujo nome é utilizado para nomear o filme, desenvolve-se em torno da divisão de dois grupos de garotos. Escolhidos por sorteio, um grupo, chamado de "polícia", tem como objetivo encontrar os membros do outro grupo, chamado de "ladrões”, que, ao sinal, saem correndo pelas ruas da cidade à procura de um esconderijo.
} 
da briga até a queda. Só depois, entretanto, da tentativa frustrada de fuga da cidade, em um barco, de Carlitos é que sua integridade moral será restabelecida. Ao tomarem ciência da inocência a partir do relato do dono da loja, as crianças se voltam para Carlitos com um ar de alegria e reconciliação. Carlitos é reintegrado ao corpo social que o havia castigado com um isolamento, olhares e agressões verbais.

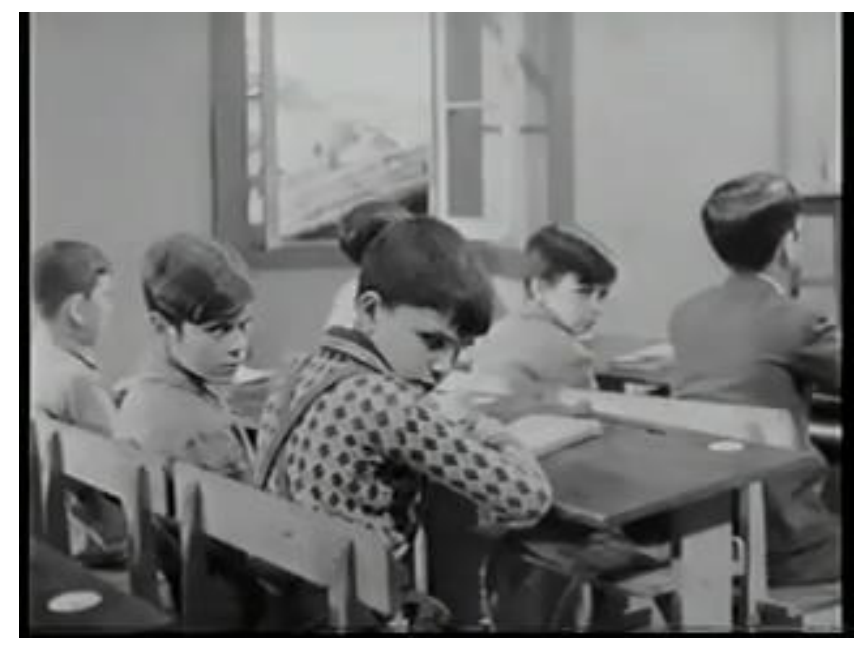

Figura 2. Alunos com olhares acusatórios para Carlitos. Fotograma de Aniki-Bóbó, 1942.

Encenado para ser um filme que aborda também a solidariedade, AnikiBóbó deixa vazar, em cenas aparentemente ingênuas, um cenário construído no qual o menor atraso deve ser motivo de castigo; o menor tropeço deve ser repreendido com a palmada; à menor distração, a pancada. Um cenário que exaspera o desejo de que se saiba tudo o que se tem de fazer: como se comportar, o que carregar, o que falar e a hora para isso acontecer; como ler, como se sentar e a forma mais correta de brincar. Não se trata de apresentar um cenário marcado pela censura e repressão que parte do Estado em direção à sociedade. Mas o filme permite vislumbrar, com grande clarividência, a emergência de uma moral sustentada na vigilância e na prospecção de valores que castravam as individualidades e procuravam costurar os desviantes à estrutura. Enfim, permite perceber que:

A identidade não é necessariamente o que somos, mas o que dizemos que somos. Ou melhor: é o que somos também por dizê-lo. A identidade - o que somos face a nós próprios e face aos outros, e com quem somos o que somos - não é independente dos discursos que produzimos a seu respeito e dos textos que deles resultam. Muitos desses discursos são narrativas, isto é, dizem a nossa identidade contando a(s) nossa(s) história(s). E são vinculações, isto é, dizem a nossa identidade especificando aquilo e aqueles a que pertencemos e aquilo e aqueles de que nos separamos. (Silva e Guerra, 2015, p. 101) 
Não é de se estranhar que tenha havido certa rejeição ao filme quando ele foi lançado. Como manifestação de um tempo e imerso em suas amarras sociais, o filme afronta a sociedade. É possível ler Aniki-Bóbó à luz do que foi mostrado, como um constructo artístico que aponta para um imaginário social marcado pela apatia e pelo medo. Talvez por isso Aniki-Bóbó, em outro lugar comum sobre sua recepção assim que lançado, tenha sido mal interpretado, ignorado e esquecido. Foi assim que parte dessa historiografia escreveu sobre o que veio depois do lançamento do filme. Sérgio Andrade, novamente em "O Porto na história do cinema", diz que:

\title{
O medo, no filme, é expressão de um universo social imerso em uma teia de conservadorismos, obrigações e saberes que conduzem ao padrão sob o risco de punições diárias
}

\begin{abstract}
Neste filme, que também, começou por ser recebido com muitas reservas pelo público e pelas críticas, e com indiferença (quando não com protestos "ofendidos") por parte da mentalidade salazarista então já instalada na sociedade portuguesa, alguns críticos veriam, mais tarde, uma antecipação do neorrealismo italiano. Outros, como Antônio-Pedro Vasconcelos, contestaram a facilidade com que se tornou lugar-comum dizer que "Aniki-Bóbó" era precursor do neorrealismo, quando, visto a distância, o que nele hoje nos impressiona é o seu lado expressionista. (Andrade, 2002, p. 47)
\end{abstract}

Carolin Ferreira (2013) segue a mesma linha, e Manuel António Pina, como a seguir um roteiro enunciativo, ressalta que o filme foi "repudiado com veemência por toda a imprensa conservadora, que o considerava 'imoral' e 'subversivo' e o chegou a classificar de 'verdadeira monstruosidade' e de 'infame cilada"; por isso mesmo teria caído "rapidamente no esquecimento" (Pina, 2015, p. 19). O que, portanto, não se comenta é sobre o choque que, eventualmente, o filme possa ter trazido para a sociedade com a qual ele desejava dialogar. Sobre as marcas e os componentes subjetivos que, embora de reconhecimento de parte do público, não satisfaziam à construção de uma imagem de sociedade. E, por fim, sobre as feridas que abria ao reconhecer a iminência de um poder que afogava as individualidades e tentava condicionar a maioria a determinado padrão.

Entre Aniki e o conto "Meninos milionários", para finalizar, evidencia-se uma sensível diferença na recepção e posterior circulação de seus discursos: sobre o primeiro, diz-se que foi esquecido no início, mas "reposicionado", anos mais tarde, como figura-chave do cinema português por sua riqueza estética e temática; sobre o segundo, há um silêncio quase que total. Ele surge, 
curiosamente, para ser jogado à margem assim que o primeiro começou a ser pensado como a síntese sensitiva de um cinema e uma alma portuguesa. No limite, o que se tem aqui é uma nova pergunta: a quem interessa Aniki-Bóbó, e não os "Meninos milionários", como representação de uma época e lugar?

\section{Considerações finais}

Ao tomar o filme Aniki-Bóbó como pretexto para refletir sobre as condições históricas que permitiram o nascimento de certa discursividade sobre a película e como sua narrativa pôde expressar um caminho interpretativo para o cinema português, este artigo quis colocar em evidência também as narrativas de produção da sócio-história. Ao manipular e manusear os textos; ao validar e significar determinados contextos e nomes; ao reforçar determinadas obras e influências, o que as narrativas fazem, além de explicar o passado fundamentado em uma perspectiva ideológica que lhes orienta, é, também esconder, subjugar, diminuir ou mesmo apagar das narrativas históricas outras possibilidades interpretativas (Jenkins, 2014). Assim, no plano das representações históricas do filme, subjazem intensos processos de construção identitária reveladores das dinâmicas de funcionamento artístico, político, econômico e social de dado país.

Portanto, nesse sentido, é importante colocar em destaque alguns pontos a título de considerações finais: 1) as leituras, em parte, da historiografia do cinema português que tomam o filme Aniki-Bóbó como tema principal, sugerem que o filme tem como argumento principal a valorização da dimensão humana, do caráter e da solidariedade. E que Manoel de Oliveira tem grande sensibilidade para tratar de temas relacionados com a "natureza humana"; 2) à luz desse argumento, colocam à margem a potencialidade do filme como arauto de uma filmografia que vê o nascimento de uma sociedade pautada por obediências, disciplinas, docilidades. Da mesma forma, uma sociedade, metaforizada no filme, em grande parte vigiada, manietada, alardeada pelo poder, que se pulveriza e atravessa diversos estratos sociais e institucionais; 3) AnikiBóbó, para representar o papel de filme-síntese que lhe colocaram, precisou, necessariamente, obscurecer o que existia à sua volta, sobretudo o que poderia ser lido como influência. Nessa senda está o conto "Meninos milionários", de Rodrigues de Freitas, que figura nessa historiografia, quando muito, como um conto que influenciou a criação de um argumento fílmico para Manoel de Oliveira; 4) ligada àquele conto paira toda uma carga de dúvidas e inquietações históricas. Ao apagá-lo ou minimizá-lo, qual o interesse da historiografia lusitana? Como substrato de uma sensibilidade juvenil rebelde, o conto, e não o filme, expressa uma maior predileção. Enfim, a que e a quem interessa/interessou manter o filme, e não o conto, como referência artística para a sociedade portuguesa nos anos 1930 e 1940 ?

Como se vê, este artigo se encerra lançando uma pergunta expressiva de uma angústia histórica. Quando se pensou na possibilidade de que Aniki-Bóbó 
pudesse responder, como repositório de informações históricas, sobre seu tempo, foi também pensando que o que se escreveu sobre ele significou/significa uma época. Ao mesmo tempo que põe em descrédito outras matrizes artísticas capazes, do mesmo modo, de projetar valores sobre sua sociedade e cultura, ao se escolher Aniki tentou-se selar e significar uma imagem sobre o passado no Porto. O filme, como um texto, é a escolha para descrever o que é uma parcela da sociedade ribeirinha do Porto nos anos 1940. Escolher Aniki como referência maior talvez responda, também, a uma necessidade premente de dizer que o medo constrói e marca profundamente uma parcela significativa de uma sociedade; mas, do mesmo modo, é possível que sua escolha parta da necessidade de dizer que por trás de um filme existe uma clareza quanto aos micropoderes que constituem essa mesma sociedade e, possivelmente, a nossa.

O fato é que Aniki-Bóbó data de uma altura em que a televisão não existia: a única imagem que havia era efetivamente o cinema. Todavia, o cinema que se fez na época não foi todo de propaganda. Embora o cinema não pudesse transpor determinados limites ideológicos, a ditadura salazarista (em conformidade com os regimes nazista, na Alemanha, e fascista, na Itália) estava mais interessada em apresentar um cinema para entreter o povo, e Aniki entrou nessa categorização. O filme traduz um caleidoscópio de poderes na estruturação da sociedade portuense da altura com foco no mundo infantojuvenil, espelhando uma sociedade fechada à qual a cultura de massas não tinha chegado - algo paradoxalmente adiado pela proeminência do Antigo Regime e pela não participação de Portugal na Segunda Guerra Mundial. Enfim, essa abordagem à obra primeira do Porto de Manoel de Oliveira pretendeu demonstrar que a criação artística é: 1) um conhecimento sócio-histórico, pois pode revelar-nos dados e fatos de interesse singular; 2) uma representação do social-histórico, de suas hierarquias econômico-culturais, de suas divisões classistas, papéis sociais, poderes institucionais e representações geracionais; 3) uma valoração do social, revelando e ocultando fatos, interpretações e atores; 4) e uma imaginação do social, transportando-nos para universos imaginários característicos de dado tempo e espaço. Aniki-Bóbó é, assim, espelho e caleidoscópio (Silva, 2012; Guerra e Silva, 2015).

Pesquisa realizada com financiamento da Coordenação de Aperfeiçoamento de Pessoal de Nivel Superior (Capes). 


\section{Referências bibliográficas}

ARAÚJO, Nelson (Org.). Manoel de Oliveira: análise estética de uma matriz cinematográfica. Lisboa: Edições 70, 2014.

ANDRADE, Sérgio C. O Porto na história do cinema. Porto: Porto, 2002.

AUERBACH, Eric. Mimesis: dargestellte Wirklichkeit in der abendländischen Literatur. Bern: Francke, 1946.

BAKHTIN, Mikhail. Estética da criação verbal. São Paulo: Martins Fontes, 2003.

BARRETO, António. Portugal na periferia do centro: mudança social. Análise social. v. XXX, n. 134, p.841-855, 1995.

BOURDIEU, Pierre. Esboço de uma teoria da prática: precedido de três estudos de etnologia cabila. Oeiras: Celta, 2002.

. O poder simbólico. Lisboa: Difel, 1989.

CALVINO, Italo. Six memos for the next millennium. Harvard: Harvard University Press, 1998. CERTEAU, Michel de. A invenção do cotidiano: 1. artes de fazer. Petrópolis: Vozes, 1994.

CORREIA, Rute Silva. Manoel de Oliveira: o homem da máquina de filmar. Alfragide: Oficina do Livro, 2015.

FERREIRA, Carolin Overhoff. O cinema português: aproximações à sua história e indisciplinaridade. São Paulo: Alameda, 2013.

FOUCAULT, Michel. Em defesa da sociedade. São Paulo: Martins Fontes, 1999. . Microfísica do poder. Rio de Janeiro: Graal, 1984.

. Vigiar e punir: o nascimento das prisões. Lisboa: Edições 70, 2013.

FREITAS, Rodrigues. Os meninos milionários na sala de aula. Presença, Folha de Arte e Crítica, Coimbra, n. 28, ago./out. 1930.

. Os meninos milionários, o jogo dos polícias e dos ladrões. Presença, Folha de Arte e Crítica, Coimbra, n. 44, abr. 1935.

GUERRA, Paula. A instável leveza do rock. Porto: Faculdade de Letras da Universidade do Porto, 2010. v. 1 .

; SILVA, Augusto Santos. Music and more than music: the approach to difference and identity in the Portuguese punk. European Journal of Cultural Studies, v. 18, n. 2, 2015.

JENKINS, Keith. A história refigurada: novas reflexões sobre uma antiga disciplina. São Paulo: Contexto, 2014.

LOFF, Manuel; PIEDADE, Filipe; SOUTELO, Luciana Castro. Ditaduras e revolução: democracia e políticas da memória. Coimbra: Almedina, 2015.

OLIVEIRA, Manoel (argumento/realização); RIBEIRO, António Lopes (produção). Aniki-Bóbó [DVD]. Portugal: ZON Lusomundo Audiovisuais, 1942.

PANOFSKY, Erwin. Architecture gothique et pensée scolastique. Paris: Éd. du Minuit, 1951.

PINA, Manuel António. Aniki-Bóbó. Porto: Porto, 2015.

SAID, Edward. Orientalism. Londres: Vintage Books, 1979.

SILVA, Augusto Santos. A mudança em Portugal, nos romances de Lídia Jorge. Sociologia: Revista da Faculdade de Letras da Universidade do Porto, n. 22, 2012.

; GUERRA, Paula. As palavras do punk. Lisboa: Alêtheia, 2015.

SILVA, Tomaz Tadeu da. A produção social da identidade e da diferença. In: (Org.).

Identidade e diferença: a perspectiva dos estudos culturais. Petrópolis: Editora Vozes, 2011.

SILVIA, Giudice Narvaz; KOLLER, Helena. Famílias e patriarcado: da prescrição normativa à subversão criativa. Psicologia \& Sociedade, v. 18, n. 1, jan./abr. 2006. 